\title{
Intelectuales mexicanos por Centroamérica: diplomáticos, activistas y estudiosos (1920-1930)
}

\author{
María del Carmen Díaz Vázquez²
}

Recepción: 19 de enero de 2015 / Aprobación: 11 de febrero de 2015

\section{Resumen}

Este trabajo muestra el vínculo existente entre México y Centroamérica en la década de 1920, posibilitado, entre otros factores, por el tránsito de intelectuales en ambas direcciones. Este movimiento trajo como consecuencia el intercambio de ideas, la confrontación de proyectos y el acercamiento diplomático. Los intelectuales desempeñaron un papel fundamental como difusores del proyecto político-nacional emergido de la Revolución de 1910 y como propagandistas de los gobiernos mexicanos posrevolucionarios. El objetivo era generar apoyo en el área, al igual que en el resto de América Latina, para hacer frente al conflicto con los Estados Unidos a raíz de la promulgación del artículo 27 que limitaba la intervención extranjera en el manejo de los recursos naturales, específicamente, el petróleo.

\section{Palabras clave}

Intelectuales, activistas, diplomáticos, México, Centroamérica

\section{Abstract}

This article shows the link between Mexico and Central America in the 1920s, enabled among other things by the movement of intellectuals in both directions. This movement resulted in the exchange of ideas, confrontation of projects, and diplomatic rapproachment. Intellectuals played a key role as disseminators of political-national project emerged from the 1910 Revolution and as propagandists of the postrevolutionary Mexican governments. The goal was to generate support in Central America, as in the rest of Latin America, to address the conflict with the United States following the enactment of Article 27 which limited foreign intervention in the management of natural resources, specifically, the oil.

1 Este trabajo forma parte de una investigación referida a la proyección y discusión del proyecto político-nacional mexicano en Centroamérica en la década de 1920 y presenta la versión ampliada de una publicación sobre el papel de los intelectuales mexicanos (Díaz, 2008).

2 Mexicana. Doctora en Historia por la Universidad de Costa Rica (UCR). Docente e Investigadora de la Universidad Autónoma de la Ciudad de México. Correo electrónico: coijuxmex@yahoo.com.mx 


\section{Keywords}

Intellectuals, activists, diplomats, Mexico, Central America

\section{Resumo}

O ensaio descreve a relação entre México e Centro América na década dos vinte, propiciada, entre outros fatores, pelo fluxo de intelectuais nos dois sentidos. O movimento acarretou o intercambio de ideias, a confrontação de projetos e uma aproximação no tema da diplomacia. Estes intelectuais desenvolveram-se como difusores do projeto político-nacional surgido da revolução mexicana de 1910 e como propagandistas dos governos da post-revolução. O objetivo foi gerar apoio local e no resto da América Latina para enfrentar o conflito com os Estados Unidos após da promulgação do artigo 27 constitucional que colocava limites à intervenção estrangeira na utilização dos recursos naturais, sobretudo do petróleo.

\section{Palavras chave}

Intelectuais, ativistas, diplomatas, México, Centro América

\section{Los intelectuales y la diplomacia}

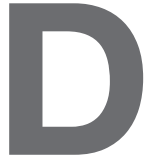

urante la segunda década del siglo XX, en México, los intelectuales se distinguieron no solo por su diletantismo en la discusión en torno a los problemas nacionales, sino también, por su la elaboración de un discurso legitimador, y, especialmente, por su participación en la ejecución de políticas concretas dirigidas a la "mexicanización" de la población indígena y al fortalecimiento del Estado posrevolucionario. Es decir, eran intelectuales orgánicos, como señalaba Gramsci, ligados a los proyectos de reconstrucción nacional y ejecutores de ciertas políticas dirigidas desde el ámbito oficial. Así, como ideólogos, hombres de ciencia, escritores, políticos y consejeros de los gobernantes contribuyeron a la elaboración de una visión dominante y dinámica de la nación, y de su devenir (Lempérière, 1988).

A partir de la proyección oficial, y, en algunos casos, desde el ámbito extraoficial, estos intelectuales establecieron vínculos con sus congéneres de la región y otras partes del mundo, contribuyendo a proyectar una imagen de México como "abanderado de la raza". Dentro de esa política de difusión cultural, se incluía el trabajo de activistas culturales, cuya labor fue reconocida en América y en Europa.

La política diplomática de esos años sentó las bases que regirían las relaciones con los países centroamericanos en años posteriores. Su actividad estuvo dirigida a contrarrestar la presión y romper el aislamiento propiciado por Estados Unidos a raíz de la promulgación del artículo 27 que afectaba sus 
intereses en el sector petrolero. Los antecedentes de esta política de acercamiento y de la incorporación de intelectuales se encuentran en los años correspondientes al gobierno de Venustiano Carranza (1917-1920) dado que sus rasgos esenciales se conforman a partir de entonces, aunque Álvaro Obregón (1920-1924) y sus colaboradores la ampliaron posteriormente.

En ese contexto, Carranza y sus colaboradores, entre ellos Isidro Fabela, idearon una campaña contraria a la norteamericana. Desde su perspectiva, resultaba indispensable extender la mirada hacia América Latina para denunciar la situación de acoso sufrida por México por parte de los Estados Unidos y también introducir informaciones que permitieran conseguir aliados que funcionaran como retaguardia internacional. Ante el panamericanismo imperante se introdujo una propuesta de corte "indoamericano", en contraposición a la Doctrina Monroe, se habló de la Doctrina Carranza. Así, "los intelectuales del carrancismo abrigaban la esperanza de servir de modelo al resto de América Latina, en el entendimiento de que posturas de esta índole tendrían mayores posibilidades de éxito si adquirían estatura continental” (Yankelevich, 1997, p. 86).

Carranza ponía especial interés en el principio de "no intervención", es decir, establecía: "la igualdad, el mutuo respeto a las instituciones y a las leyes, y a la firme y constante voluntad de no intervenir jamás, bajo ningún pretexto, en los asuntos interiores de otros países, han sido los principios fundamentales de la política internacional que el Ejecutivo de mi cargo ha seguido" (Carranza citado por Galindo, 1919, p. 40). Estas ideas encontraron un buen asidero en Latinoamérica dado que las corrientes intelectuales de la época eran receptivas al proyecto porque se contraponía a la preponderancia y a la intervención norteamericana por medio de la política del "big stick" y la "diplomacia del dólar". México aspiraba, entonces, a convertirse en un modelo de conducta internacional y de reformismo social.

La diplomacia de Carranza se desarrolló por canales formales e informales. Bajo este régimen, se inauguró un trabajo diplomático que sentaba las bases de una presencia mexicana que se proyectaría hasta 1930. Se organizaron misiones especiales de propagandistas a sueldo que recorrían el continente. Representantes obreros y estudiantes universitarios se desplazaron por los diferentes países, mientras se ponía en marcha un sólido trabajo publicitario, a través de las líneas telegráficas y del correo regular. El carrancismo apuntó a distintos sectores: gobierno y cancillería, partidos políticos, escritores, intelectuales y prensa en general (Yankelevich, 1997).

La necesidad de alcanzar el reconocimiento estadounidense obligó al presidente Álvaro Obregón a reactivar y fortalecer los dispositivos activados años atrás por Carranza. Así, la diplomacia mexicana, destacada por tener como representantes a hombres de letras (Amado Nervo, Federico Gamboa, Alfonso Reyes, Carlos Pellicer, Alfonso Cravioto, Juan de Dios Bojórquez, Antonio Médiz Bolio, entre otros), se fue acercando a los espacios de 
la cultura latinoamericana. Al respecto cabe destacar el peso del trabajo de José Vasconcelos en la construcción de una imagen altamente favorable a México, exponiendo la confluencia del proyecto educativo y cultural mexicano en el ámbito estudiantil e intelectual.

La política educativa y cultural difundida a todo el continente incluía y reclamaba la participación de los intelectuales de América Latina. De esta manera, el nacionalismo cultural y la lucha en defensa de la soberanía aparecían como resultado de una experiencia revolucionaria que sería calificada como "vanguardia" del continente. La diplomacia mexicana a nivel continental fue comparada con la ateniense, por incluir intelectuales, poetas, escritores y filósofos:

Ahora preguntamos, ¿por qué México se aparta en esto de la costumbre seguida por sus hermanos del continente? Nos respondemos: porque México le da a la diplomacia un grave y superior sentido que quizá desconocen otros países; porque en la República Mexicana, al revés de lo que pasa en otros de Hispanoamérica, cada hombre de estado... es una suerte de mecenas nato y espontáneo; y porque en México la revolución que derrocó la dictadura porfiriana, trajo el advenimiento de una genuina democracia (Rosales, 1 de marzo de 1924, p. 3).

La nota del periodista hondureño, Salatiel Rosales, agregaba que en México era donde más acceso se daba al elemento intelectual y al ambiente diplomático, incluso bajo la "ilustrada y progresista dictadura porfiriana". Los gobiernos revolucionarios, "en medio de sus extravíos", también daban preferencia a las "elites mentales". Esta política debía ser tomada como ejemplo por el resto de los países latinoamericanos porque solo los intelectuales podían ser los portadores de esos "mensajes profundos de la espiritualidad que enseñarán a los pueblos y razas afines a conocerse y amarse" (Rosales, 1 de marzo 1924, p. 3).

\section{México-Centroamérica: entre la cercanía y el conflicto}

De acuerdo con los objetivos y principios señalados, México emprendería una afanosa campaña en Centroamérica, la cual se dirigía hacia diversos frentes. Ante esta situación, en 1921, el cónsul francés Paul Serre informaba del viaje de una misión diplomática mexicana (“iencore une!”, jotra más!) compuesta por el poeta, periodista y diplomático Juan B. Delgado, nombrado entonces como enviado extraordinario y ministro plenipotenciario en misión especial, tres secretarios y un agregado militar, entre otros, para agradecer a los países de América Central (Guatemala, Salvador y Honduras) por haber enviado representantes a la ceremonia de toma de poder del Presidente Álvaro Obregón. Gracias a la "indiscreción" de un periodista de San José (Costa Rica), el representante francés se enteró de que Delgado tenía una misión "secreta" en las cinco repúblicas: estudiar la posibilidad de que México, "orgullo y salvaguardia de la América Española", se uniera a la Federación de Centroamérica en la que se empleaban activamente los gobiernos de Guatemala, Honduras, 
el Salvador y Costa Rica (Boulletin periodique de la presse Sud-americaine, 20 de mayo de 1921).

El interés de México por convertirse en la "vanguardia" de Centroamérica generó cierta desconfianza en los países de la región, incluso, se le llegó a considerar interventor en asuntos que no le competían. Una declaración oficial del poeta y periodista Antonio Mediz Bolio, Ministro de México en Nicaragua, referente a las condiciones políticas que privaban en el país de su residencia, propició un incidente entre ambos países. El diario El Comercio ridiculizaba el rol del mentor que asumía México y "por una ironía suprema del destino, el gobierno de Calles se erige públicamente en juez moral de las cuestiones internacionales" (El Comercio, 27 de enero de 1926).

Avanzada la década de 1920, el escritor y político guatemalteco, Virgilio Rodríguez Beteta, quien fue nombrado mediador del conflicto de límites entre Guatemala y Honduras, sintetizaba la visión de la política mexicana en el sector de la elite diplomática y política guatemalteca:

Guatemala se encuentra entre la espada y la pared; la espada es México, con sus carantoñas, sus aeroplanos obsequiados, sus torres inalámbricas, su Agencia Ariel, sus activísimos Bojórquez, sus inteligentísimos braviotos [se refiere a Alfonso Cravioto], sus lentas pero bien compactadas y penetrantes propagandas, sus revoluciones, sus asesinatos, etcétera. México se gasta fuerte sumas en su propaganda dentro de Guatemala (Rodríguez Beteta, 1980, p. 59).

La insistente política mexicana no convencía a Rodríguez Beteta, al igual que a otros guatemaltecos, porque consideraba que en 1928 México ya no tenía las ideas con respecto a Guatemala de "los generosos Vasconcelos", refiriéndose a la política de acercamiento diseñada por el, entonces, Secretario de Educación Pública. Además, consideraba que ya era tarde para que México cambiara su política porque había "muchas heridas en el alma" y su actitud resultaba sospechosa por llevarse a cabo en un momento de presión por parte de los Estados Unidos. A esto se sumaban sus doctrinas del "más subido socialismo". Dada esta situación era preferible la alianza con los Estados Unidos a pesar del dominio ejercido por este país (Rodríguez Beteta, 1980, p. 59).

La diplomáticos mexicanos conocían la postura de Rodríguez Beteta, por eso no era de su agrado. En un informe de Juan de Dios Bojórquez, enviado extraordinario y ministro plenipotenciario en Guatemala, ante su posible designación como representante diplomático de Guatemala en México, señalaba, en 1922, su inconveniencia porque era públicamente conocida su profunda antipatía hacia todo lo mexicano, incluidas las instituciones, gobernantes y hasta las costumbres (Aguirre Velásquez-su expediente, 1922).

Entonces, pese a las "cordiales" relaciones, el afán del gobierno mexicano por convertirse en evaluador de los acontecimientos políticos en Centroamérica le generaba reacciones encontradas en Guatemala. Una moción del parlamento mexicano votó por la pertinencia de apoyar el golpe de Estado 
de los liberales en contra de Herrera en diciembre de 1921, las reacciones de protesta no se hicieron esperar: los más moderados señalaron que México debería ocuparse de sus asuntos. Otros criticaron su afán por convertirse en un ejemplo cuando había roto todos los registros de pronunciamientos, de golpes de Estado y de revoluciones, además, ni siquiera había conseguido el reconocimiento de su gobierno por las potencias extranjeras.

El gobierno de Obregón aceptó el "ridículo inconveniente" de la moción del parlamento mexicano, señalando, a través del agregado en Guatemala, que su país sería el primero en reconocer la soberanía de las repúblicas vecinas y que jamás intervendría en la política interior de Guatemala. Esta declaración calmó las susceptibilidades guatemaltecas, luego de que México le dio la espalda a un exiliado unionista por realizar propaganda.

Según lo muestran las fuentes consultadas durante los años de gobierno de Carlos Herrera y Luna y José María Orellana (1921-1926), las relaciones de Guatemala con México en general fueron cordiales. Por ejemplo, en uno de sus informes, Orellana señalaba que las relaciones con el país vecino "habían adquirido una inusitada cordialidad". Alfonso Cravioto, representante diplomático en Guatemala (1926-1928), se había encargado de ofrecer banquetes, enviar una banda musical, un jaripeo en honor del presidente guatemalteco -Orellana-, además, Plutarco Elías Calles determinó elevar la legación en dicho país al rango de embajada en 1926 (Aguilar de León, 1986, p. 251) justo cuando enfrentaba problemas con su homólogo estadounidense. Al respecto el presidente mexicano mencionaba:

La elevación de nuestra representación diplomática en Guatemala no significa simplemente aumentar nuestra representación en el orden protocolario, sino que ha respondido a la sincera política del gobierno mexicano, de aprovechar este medio para patentizar los sentimientos de cordialidad que norman nuestras relaciones con los demás países de nuestra raza (Los presidentes de México ante la nación, 1966, citado por Toussaint, 2001, pp. 149-150).

No obstante, las demás representaciones mexicanas en Centroamérica fueron transformadas en embajadas hasta 1943. Guatemala, correspondiendo a la iniciativa mexicana, elevó a ese rango su representación en México, nombrando como primer embajador a Eduardo Aguirre Velásquez, propietario del periódico Excelsior. En el marco de esa estrategia, México creó las embajadas de Argentina y Cuba, en Brasil y Estados Unidos ya contaba con ellas.

En unión a la medida anterior, el gobierno mexicano hizo efectivo el envío de un avión, bautizado con el nombre de "Benito Juárez", llevado a Guatemala por una comisión militar. En 1925, el suceso más importante había sido la inauguración del servicio radio-telegráfico entre ambos países, aprovechando la instalación que otorgó el gobierno de México. Así la Estación Chapultepec recibía todos los días mensajes radio-telegráficos de la Estación de Guatemala sin ninguna dificultad ("Informe de la Legación de Guatemala en México", 1925). 
Como hemos señalado, la política mexicana generó simpatía en los sectores intelectuales guatemaltecos, pero también desconfianza. Algunos informes diplomáticos enviados por la representación guatemalteca desde México, mostraban las causas del descontento hacia la política interior y exterior impulsada por el gobierno de ese país. Esto se resumía en los siguientes puntos: a) la exagerada propaganda de la prosperidad y riqueza en recursos naturales de México propició que muchos guatemaltecos emigraran a ese país, enfrentándose con serias dificultades laborales; b) las constantes huelgas y "los despojos del sistema agrarista" o "comunismo aplicado a la propiedad rural". Se esperaba que su influencia no llegara a Guatemala; c) la falta de reconocimiento de los gobiernos posrevolucionarios por parte de Estados Unidos; d) las excursiones fomentadas por México para que ciudadanos guatemaltecos visitaran ese país no era de ninguna utilidad para Guatemala. Se sugería que era mejor tener un agente agrícola que observara las experiencias y las novedades en ese ramo; d) la falta de conocimiento de sus "intimidades como Nación" se evidenciaba en las noticias y comentarios aparecidos en los periódicos mexicanos (Informes políticos, 1922 y 1923).

En ese contexto de desconfianza mutua, políticas de acercamiento y críticas a la política mexicana, los intelectuales como diplomáticos, propagandistas y estudiosos trabajaron arduamente en la búsqueda del afianzamiento de las relaciones de México con Centroamérica.

\section{José Vasconcelos}

De acuerdo con la consulta periodística realizada en relación con la presencia de México en Centroamérica, destaca la figura de José Vasconcelos (1882-1959), quien, en el círculo de intelectuales y estudiantes, fue considerado como un maestro de la juventud, como el centro del movimiento ideológico que se estaba desarrollando en México y como alguien que había posibilitado el acercamiento entre México y Guatemala. Su labor era más valorada que la de los gobiernos, como si sus propuestas fueran independientes de la política impulsada por los gobernantes mexicanos, principalmente, por el de Obregón. Sin embargo, tuvo cierta autonomía en relación con la importancia que atribuyó al acercamiento político y cultural, de manera especial, con Guatemala. Así se ganó la confianza y simpatía de los intelectuales guatemaltecos para lograr su objetivo, a través de la difusión del proyecto cultural mexicano, tal y como lo hemos señalado.

Vasconcelos, inició su tarea educativa al ser nombrado por Adolfo de la Huerta como rector de la Universidad Nacional el 4 de junio de 1920, cargo en el que permaneció hasta el 10 de octubre de 1921. Después, se ocuparía de la Secretaría de Educación Pública en cuya creación había estado involucrado al proponer, el 22 de octubre de 1922, a los diputados una Proyecto de ley para 
la creación de una Secretaría de Educación Pública Federal, cuya discusión se venía dando en la prensa desde el mes de septiembre (Fell, 1989, p. 21).

Finalmente, el presidente Obregón introdujo la iniciativa al Congreso y, así, la Secretaría fue creada el 28 de septiembre de 1921 y Vasconcelos fue nombrado Secretario de Educación. A la nueva Secretaría de Educación Pública (SEP) se le asignó un presupuesto mucho mayor que el otorgado en los gobiernos predecesores. Algunas de las prioridades de su nuevo encargo fueron las siguientes: la educación indígena para asimilar la población marginal; la educación rural para mejorar el nivel de vida del campo mexicano y la educación técnica para elevar el de las ciudades así como la creación de bibliotecas, publicación de libros populares, popularización de la cultura, entre otras (Vázquez, 1979, p. 139).

El trabajo que Vasconcelos realizó como rector de la Universidad Nacional y luego como Secretario de Educación Pública se vinculó con una idea central en su pensamiento: convertir a México en punto de encuentro cultural para toda la América Latina. Para lograr tal fin, diseñó y apoyó diversas estrategias, entre ellas, la realización, en 1921, del Congreso Internacional de Estudiantes, lo cual coincidió con la celebración del centenario de la Independencia de México y otros países de América Latina. El evento fue organizado por la Federación de Estudiantes de México, en cooperación con la Liga Panamericana de Estudiantes de Nueva York. La paternidad del congreso se la atribuyó Daniel Cosío Villegas en sus Memorias. Fuera de la discusión de si la idea fue de Vasconcelos o no, lo cierto es que este joven intelectual fue una figura clave en el ámbito estudiantil, por lo que obtuvo el reconocimiento de los delegados de los otros países. A iniciativa de la delegación centroamericana fue nombrado presidente de dicho evento (Cosío Villegas, 1986).

De ese congreso, los estudiantes se llevaron de México la imagen de un país que marchaba a la vanguardia después de la Revolución, además, fortalecieron el apoyo a la unidad latinoamericana y llevaron a sus respectivos países las ideas del proyecto educativo de Vasconcelos, quien los consideraba parte de la élite intelectual que podía acercarse a la cultura occidental y les confería el carácter de fuerza renovadora de la humanidad.

El político y filósofo mexicano consideraba necesario llevar la universidad a la calle y expandir su actividad docente por medio de la denominada "extensión universitaria". Por tal razón, durante este congreso, el tema de las universidades populares adquirió relevancia y en una de sus resoluciones señalaba la obligación de crearlas.

El interés en los estudiantes, como receptores y propagandistas del modelo nacional mexicano, también se expresó en el plan de becas otorgadas por el gobierno, con el impulso de Vasconcelos y Bojórquez, para jóvenes centroamericanos matriculados en escuelas mexicanas. Sobre el tema volveremos más adelante. 
Además, como encargado de la SEP emprendió una amplia distribución de libros y revistas publicados por dicha institución. Así propició que esta adquiriera fama en los países de habla hispana por las ediciones de clásicos: El Maestro-Revista Nacional, El libro y el pueblo, entre otras publicaciones.

En el ámbito intelectual centroamericano, la distribución de libros fue considerada como una labor de "regeneración cultural", por eso se elogiaba la publicación de obras de literatura clásica que se repartían para "lograr la depuración del gusto popular tantas veces descarriado por falsas corrientes estéticas" ("Laudable labor de la Secretaría de Educación Pública de México", 13 de noviembre de 1922, p. 1). Además, se consideraba de gran relevancia la fundación de algunas bibliotecas "bajo los auspicios de la Patria de Juárez" y muchos de los intelectuales habían sido obsequiados con un lote de valiosos ejemplares. Tales acciones motivaban a los editorialistas de El Imparcial a señalar que en México se poseía "la locura del libro" y la relacionaban atinadamente con la exaltación ideológica del proceso de transformación emprendido a raíz de la Revolución. En contraparte criticaban las trabas a la entrada de los paquetes de libros obsequiados por México (Hemiplejia de la educación. El libro caro, El Imparcial, 24 de mayo, 1923, p. 3, citado por Díaz, 2008, p. 2064).

Si bien existían dificultades para el intercambio de libros entre México, Centroamérica y el resto de América Latina, resultaba relativamente más sencillo introducirlos por la vía oficial a través de los encargados de las legaciones en la región, como en el caso de Juan de Dios Bojórquez, quien posiblemente fue el más activo de los intelectuales-diplomáticos que recorrieron los países centroamericanos y que establecieron relaciones con estudiantes, periodistas y obreros.

El 3 de junio de 1922, en un acto protocolario para celebrar el centenario de las independencias centroamericanas, Bojórquez, entonces como delegado universitario, entregó libros a sociedades obreras de Honduras, Confederación Obrera de Tegucigalpa y la Sociedad de Obreros de Amapala, y a los obreros de León, Nicaragua. Con los libros donados se crearon bibliotecas que llevaron nombres de reconocidos personajes mexicanos (García, 2010). El reparto de materiales bibliográficos también se dirigió a bibliotecas del interior de Guatemala y a las sedes de la Universidad Popular, institución creada en la década de 1920 a partir de una idea difundida por Vasconcelos, como mencionamos en líneas anteriores.

Entre las publicaciones donadas, El libro y el pueblo llamó la atención de los sectores intelectuales. Se le llegó a considerar un material importante debido a que mostraba la fase de desarrollo del movimiento educativo mexicano. Además de los datos bibliográficos que proporcionaba la revista, difundía "una idea germinal, elevada... la idea de la América libre y activa de su papel en la gran obra de rectificar y elevar la civilización" (El Imparcial, 5 de mayo, 1923, p. 3). Así, México revelaba en sus revistas, en sus libros, en sus boletines, una 
lucha intensa por las ideas y una revolución tan vasta, "como acaso no existe hoy en otro pueblo del mundo" (El Imparcial, 5 de mayo, 1923, p. 3). En 1925, la SEP de México obsequió 175 volúmenes de libros para formar la base de las cinco bibliotecas infantiles que instalaría la Sociedad Protectora de la Niñez. El donativo fue gestionado por José Guillermo Salazar, guatemalteco residente en la capital mexicana (Bibliotecas de la Casa del Niño. Valioso donativo de la Secretaría de Educación Pública de México, 3 de junio de 1925, El Imparcial, p. 1, citado por Díaz, p. 2065).

Como se puede observar, los comentarios de El imparcial, expresaban el impacto de una política de difusión donde el contenido de las revistas que hemos mencionado estaba encaminado a lograr determinado fin:

Promover el nivel cultural del pueblo, hacer publicidad sobre lo realizado por los mexicanos (bibliotecas, obras obsequiadas) y favorecer el intercambio entre el centro (México) y la periferia (otros países latinoamericanos, Estados Unidos, Europa), entre el Gobierno y el pueblo (Bodo, 2004, p. 57).

Por eso Bojórquez envía informes desde Centroamérica, los cuales se publican en las revistas y Vasconcelos escribe sobre los principios que deberían regir la relación de México con la región. Las ideas de Vaconcelos tuvieron un impacto considerable en Centroamérica y en el resto de América Latina, convirtiéndose en la figura continentalista que, posiblemente, destacó más en las publicaciones de la intelectualidad de la región en la década de 1920. Por eso, ocupó las primeras planas en los principales diarios de Costa Rica y de Guatemala, además, le rindieron homenajes, que despertaron el interés de los sectores medios (La Tribuna, 6 de abril, 1930, p. 1). Joaquín García Monge en Repertorio Americano, semanario que reunía a los pensadores latinoamericanos más representativos de la época, dedicó gran espacio a Vasconcelos y sus disertaciones filosóficas. En su calidad de embajador cultural tuvo una presencia fuerte y prestigiada, pero cuando pretendió difundir su causa política a través de ataques a la Revolución y sus gobernantes, la recepción oficial tendió a variar, esto a partir de la década de 1930 (Díaz, 2008b, p. 2063).

El diario El Imparcial, considerado como un centro donde confluían los mexicanistas, dedicó espacios importantes para mostrar la grandeza de México y la labor realizada por el Secretario de Educación. Además, se reconocía que las buenas relaciones de este país y Guatemala estaban vinculadas con la política de acercamiento cultural impulsada por él. Al respecto se difundían las palabras de Vasconcelos: "México desea estrechar más las relaciones con las repúblicas hermanas del sur; y espero que mi misión contribuya a convertir en realidad sus deseos" (Vasconcelos citado por Díaz, 2008, p. 2063).

Desde la perspectiva de Vasconcelos, para fortalecer esas relaciones no bastaba con el simple intercambio de notas diplomáticas y atenciones. Esperaba la llegada de un presidente audaz que clausurara las aduanas de la frontera 210 con Guatemala, desistiera de nombrar recaudadores y fiscales para no cobrar 
los derechos, dejando los caminos para el libre tránsito. Si Guatemala no correspondía otorgando iguales franquicias, no importaba porque el beneficio moral y económico de abolir una frontera era inmenso. Señalaba, además, que su plan no era de predomino, de ventaja del más fuerte y mucho menos de interés en una posible integración guatemalteca a la federación, porque "queremos a Guatemala independiente, a Guatemala libre; más aún, queremos que en el Sur se funde un nuevo Estado, el Estado de Centro América, mientras más poderoso sea, más admirable. Tal debe ser la prueba plena de nuestra lealtad" (Anales de la Sociedad de Geografía e Historia, 30 de junio de 1925). Esta disertación del filósofo mexicano tuvo una recepción importante en Guatemala, tanto que en años posteriores se le siguieron rindiendo homenajes.

\section{Juan de Dios Bojórquez}

En la búsqueda de mayores contactos con Centroamérica, quien desempeñó un papel fundamental, por las diversas e intensas actividades realizadas en la región, fue el escritor, político y agrónomo sonorense Juan de Dios Bojórquez (1892-1967). Este personaje se insertó en el proceso revolucionario en 1913, apoyando a la fracción constitucionalista, encabezada por Venustiano Carranza. A partir de ese momento inició una intensa vida política, diplomática y periodística. Como escritor, cuyo seudónimo era Djed Bojórquez, desarrolló diversos géneros como novela, relato, biografías, crónicas y ensayos (Galeana, 2014, pp. 10-11). Su participación en el proceso revolucionario le permitió relacionarse con importantes caudillos, entre ellos, sus paisanos, los sonorenses Álvaro Obregón y Plutarco Elías Calles, miembros del llamado grupo Sonora, quienes dominarían la escena política mexicana en la década de 1920.

En una amplia entrevista realizada a Bojórquez, en 1964, él narra cómo iniciaron sus periplos por Centroamérica. En 1919, fue llamado por Pastor Rouaix, otro destacado constitucionalista, para formar parte de la "Delegación Comercial Mexicana", iniciativa que formaba parte del proyecto de Carranza para acercarse a la región. Al respecto Bojórquez señala:

Era una delegación comercial que yo le aseguro que en México todavía no se ha hecho otro ensayo mejor que eso: llevamos 110 cajas de grandes dimensiones, llenas de muestra de todo lo que entonces producía México; de todo, telas, petróleo, aceites. Bueno, una cosa bonita: cervezas, de todo. Y así fuimos a Guatemala. Allá inauguramos el 15 de diciembre de 1919 esa exposición. Y estuvimos hasta el quince de enero de 1920 (Bojórquez citado por Wilkie y Monzón, 2001, pp. 329-330).

Con esta exposición recorrió El Salvador, Honduras y Costa Rica. En estos viajes, realizó diversas actividades vinculadas con la política y la cultura, por ejemplo, se relacionó con algunos opositores del régimen de Estrada Cabrera, aunque también se comunicó con él, dio conferencias sobre poesía y escritores mexicanos, y entabló comunicación con intelectuales de cada país. 
Posteriormente volvería a la región por indicaciones de Obregón al enterarse del intento de unión de las cinco repúblicas:

Sobre eso tengo una cosa muy interesante que nunca la he dicho. ¿Quiere que se la suelte aquí? Mire, a mí me dijo Obregón que quería que fuera a ver, y que ayudara a aquella gente. Primero habían dicho que eran los cinco países. Eso fue en 1921, que se iban a unir. Pero a última hora sólo fueron Guatemala, Honduras y El Salvador (Bojórquez citado por Wilkie y Monzón, 2001, p. 332).

Para el sonorense, el hecho de que los líderes unionistas, específicamente se refiere a al nicaragüense Salvador Mendieta y al hondureño Salvador Corleto, no hubieran sido "hombres de acción" presentó un problema para la creación de un ejército, asunto que él consideraba necesario para evitar que la unión fracasara, por eso se dirigió al presidente mexicano pidiéndole armas, este respondió afirmativamente:

Estaba dispuesto a mandarme las armas a la frontera, al Suchiate. Creo que habíamos hablado de hasta diez mil rifles, algunos cañones, máuseres, que iban a mandar; y quién sabe cuántos millones de cartuchos y ametralladoras. Todo estaba listo. Y hasta tenía yo la persona que iba a venir por eso. Pero a la hora de la hora ya no quisieron (Bojórquez citado por Wilkie y Monzón, 2001, p. 332).

Finalmente, el intento de unión centroamericana, fracasó, desde la perspectiva del diplomático, porque sus líderes no pudieron defenderla. En ese contexto, con el apoyo de la United Fruit Company, en 1921, se dio el golpe de Estado que destituyó a Carlos Herrera y llevó al poder a José María Orellana. A pesar del apoyo de Bojórquez hacia los unionistas, terminó siendo buen amigo del presidente guatemalteco.

De 1921 a 1922, Bojórquez estuvo en Honduras, como Ministro Residente de México ante ese país y delegado de la Universidad Nacional de México en Centroamérica. En 1923, fue designado Enviado Extraordinario y Ministro Plenipotenciario en Guatemala, permaneció en este país hasta 1924, cuando Plutarco Elías Calles tomó posesión de la presidencia, entonces fue nombrado director general de Agricultura, dependiente de la Secretaría de Agricultura y Ganadería.

Bojórquez, en su accionar en Centroamérica, mostró gran versatilidad: así como participó en el proyecto de unión de las cinco repúblicas de Centroamérica, también sus esfuerzos se dirigieron hacia actividades vinculadas al ámbito cultural y deportivo. Al respecto recuerda haber llevado a Guatemala al "Club de Futbol América" y a la "Banda del Estado Mayor". Estas iniciativas eran del agrado de Orellana. Bojórquez relata el impacto que tuvo la mencionada banda en Guatemala:

Fijese, esa banda era tan buena, que cuando íbamos a Guatemala se alineó allí en la estación -era una noche así de esas de "chipichipi", que hay allá mucho, de la lluvia menuda- y el maestro, un gran músico aquí de Durango, se llamaba 212 Melquíades Campos, alineó a los mexicanos y les dijo: "El Himno Nacional de 
Guatemala”. Y lo tocó como no lo habían oído. ¡Bueno, fue un escándalo! La gente lloraba de gusto. Viera usted qué escándalo armó. Bueno, les tocó el himno, como nunca, y es un himno precioso... Bueno, pues después de El Salvador me pidieron la banda... Y le dieron una batuta de oro. ¡Qué tal músico sería! (Bojórquez citado por Wilkie y Monzón, 2001, p. 333).

La Banda del Estado Mayor, dirigida por Melquíades Campos, no solo estuvo en Centroamérica, sino también en Estados Unidos y Sudamérica. En 1922, formó parte de la numerosa delegación mexicana, encabezada por Vasconcelos, la cual incluía militares, intelectuales y artistas, que acudió a los festejos de la independencia de Brasil (Crespo, 2005, p. 219). Para esta ocasión compuso la marcha "Cuauhtémoc" la cual fue interpretada al momento de la entrega, por parte de los enviados mexicanos a los brasileños, frente a la estatua del emperador mexica.

Como se puede observar, el trabajo desempeñado por Bojórquez oscilaba entre lo confidencial y lo público, entre lo político y lo cultural. En ese sentido, él recuerda que se encontraba en México durante la rebelión de Adolfo de la Huerta (1923), quien se oponía a la designación de Calles como candidato a la presidencia, entonces había traído un equipo de fútbol guatemalteco, el cual tuvo que regresar por Nueva Orleans porque la comunicación por el sur estaba interrumpida. Ante las indicaciones de Obregón, él también regresó a Guatemala por la misma ruta. Entonces, el presidente mexicano le asignó otra misión especial:

Las tropas que habían quedado aisladas al otro lado del istmo. Y me tocó atender allí las tropas de Juan de Domínguez y de Bravo Izquierdo. Yo les llevé de Guatemala provisiones de boca, petróleo, dinero, cuanto hay, medicinas. A Obregón le gustó mucho lo que hice en aquella época. Incluso hicimos hasta un oleoducto para pasar por el Suchiate, el petróleo a las máquinas de aquel lado (Bojórquez citado por Wilkie y Monzón, 2001, p. 334).

Años después Bojórquez señalaría que los "mejores frutos", del acercamiento que se había conseguido con Guatemala, se hicieron más visibles a fines de 1923 y 1924. Ante la rebelión delahuertista, el presidente Orellana puso de relieve la simpatía que sentía por México al permitir, desde el territorio guatemalteco, la entrada de todos los elementos de guerra necesarios para sostener al ejército leal al gobierno de Obregón que se encontraba en el Istmo de Tehuantepec y Chiapas (Bojórquez, 1963, p. 198).

Las labores de Bojórquez fueron tan intensas que, como veremos más adelante, se le llegó a acusar de "abarcarlo todo en Centroamérica". Incluso, sus puntos de interés se dirigieron también a asuntos vinculados con la comunicación. Por eso, se relacionó con la donación del gobierno mexicano de las primeras estaciones receptoras de radio existentes en Guatemala y a la formación de la Agencia Trens que empezó a enviar noticias de México a los cinco países centroamericanos con la finalidad de "borrar muchos prejuicios" (El Heraldo, 24 de agosto de 1923, p. 1). Para adelantarse a la crítica de que 
las estaciones servían para hacer propaganda de México, estas fueron transformadas en transmisoras. Así las noticias de un país llegaban a los otros y, también, a México, en donde se recogían en boletines especiales, que eran impresos para ser enviados a los círculos oficiales, a bibliotecas públicas y a la prensa (Díaz, 2008b, pp. 2073-2074).

Otro ámbito que estuvo en la esfera de la influencia de Bojórquez (relacionado con la política educativa de Vasconcelos) fue la formación de las primeras bibliotecas centroamericanas, las cuales también fueron obsequio del gobierno mexicano. Él instaló la Biblioteca México en Guatemala, primero en la casa que ocupaba la legación y, más tarde, en un edificio acondicionado especialmente para eso. El sonorense nombró a Rafael Arévalo Martínez, considerado entonces como el "primer escritor guatemalteco", director de la primera Biblioteca México (1924). Años después, Bojórquez seguiría considerando a Arévalo como el poeta más importante de Centroamérica y como uno de los cinco más destacados del continente (Bojórquez, 1963, p. 199).

El contacto del escritor guatemalteco con Bojórquez, el "gran apóstol de la propaganda antiyanqui en Centroamérica", como lo nombraba el embajador francés en Guatemala, influyó para que escribiera la novela La oficina de paz Orolandia (Arévalo, 1925). Esta fue dedicada a Bojórquez y a México: "mi deuda con su patria, anterior a la que he contraído con usted, no es menos grande". En dicha novela, el autor criticaba la presencia abarcadora del imperialismo norteamericano, por ello se subtitulaba "Novela de imperialismo yanqui". En ella abordaba abiertamente los efectos negativos del régimen concesionario en toda Centroamérica y los poderes excesivos de la United Fruit Company (UFCO) y la International Railways of Central América (IRCA). Además de su crítica al imperialismo, reconocía el liderazgo intelectual de Vasconcelos.

Como señala Arturo Taracena (octubre-diciembre de 2010, p. 6), además de la relación con importantes escritores, Bojórquez también realizó labor propagandística de la Revolución mexicana en dos obras políticas y en novelas, obras publicadas todas en Guatemala: Crónicas de México. Calles (1923), La actual situación de México (1924) y Yorem Tamehua (1923). Seguramente estos trabajos fueron leídos por los intelectuales que escribían en El Imparcial porque se publicaron artículos que hacían referencia a las temáticas tratadas por el diplomático mexicano y que planteaban la idea de México como un modelo de nación para Centroamérica.

El intenso trabajo de Bojórquez en el istmo no siempre recibió el apoyo requerido desde México. Ante esta situación, en 1922, el diplomático escribió a Alberto J. Pani, Secretario de Relaciones Exteriores de México, destacando las misiones que desempeñaba en Guatemala y en Centroamérica, para renunciar a su cargo de ministro, renuncia que no fue aceptada y en su correspondencia 214 diplomática no volvió a mencionar el asunto. 
La protesta del enviado mexicano estaba relacionada con el hecho de que no se había respetado su nombramiento como delegado de la Universidad Nacional (le había sido concedido por Vasconcelos, entonces rector de la Universidad, y corroborado por el presidente Álvaro Obregón). Dicho nombramiento tenía como objetivo lograr un mayor acercamiento entre estudiantes mexicanos y centroamericanos y fundar, en los cinco países del Istmo, bibliotecas populares. Sin embargo, para el envío de becarios, se desautorizaron sus atribuciones de delegado universitario, poniéndolo en mal predicamento ante las legaciones de México en Costa Rica y Nicaragua. Bojórquez consideraba que el gobierno mexicano cometía un error al ordenar que las becas se concedieran por conducto de los gobiernos, porque en "en vez de beneficiar a una nación, convierte el valioso obsequio en botín político, que el gobierno de El Salvador y Nicaragua emplearán para comprometer a sus enemigos, o fortalecer alianzas con morbosos elementos de sus carcomidas administraciones" (Bojórquez-su expediente, 1923-1924, citado por Díaz, 2008b, p. 2075).

La correspondencia diplomática del ministro, expresa con claridad el funcionamiento de la triada para Centroamérica: Obregón-Vasconcelos-Bojórquez, por lo menos para los primeros años de la década de 1920, periodo en que fue más evidente la intensa política mexicana de acercamiento hacia esta región. La asignación de becas a centroamericanos era uno de los elementos centrales de dicha política.

Bojórquez, como Vasconcelos, consideraba que el vínculo con los estudiantes permitiría un mayor acercamiento con los pueblos centroamericanos debido a que algunos profesionistas "eran tan mexicanos como nosotros" y hacían la mejor propaganda de México en el extranjero. Un ejemplo, destacado, de esta afirmación fue el trabajo desempeñado por el hondureño Rafael Heliodoro Valle. La idea de las becas, agradó a Obregón, quien sugirió que se otorgaran 60 para estudiantes de esta región, 12 por cada país. La indicación se trasladó a Vasconcelos para que oficializara el acuerdo (el cual se firmó el 19 de octubre de 1921) y Bojórquez se encargó, en calidad de delegado de la Universidad, de dar la noticia en el Istmo (Bojórquez-su expediente, 1923-1924). El 17 de noviembre de 1921, la Secretaría de Guerra anunció que concedía 15 becas para el Colegio Militar y cinco para la Escuela de Aviación.

Según Bojórquez nunca fue su intención abarcarlo todo en Centroamérica, aunque pudiera parecer que así fuera. Él pretendía que los Ministros o Encargados de Legaciones de México contaran con el apoyo de Ministros de Instrucción o profesores distinguidos para garantizar la buena distribución de las becas. En Costa Rica, contó con el exMinistro de Instrucción, Joaquín García Monge. Sin embargo, el plan diseñado por Bojórquez no recibió el apoyo del representante mexicano en El Salvador, J. M. Ferrer, quien, según sus palabras, se preocupaba más por defender al gobierno salvadoreño que por trabajar a favor de México. 
Las impresiones del sonorense muestran que estaba al tanto de lo que ocurría en la región y se mostraba presto a enviar la información a México. Él asumía que era quien más conocimiento tenía de los cinco países centroamericanos, por eso sus opiniones deberían considerarse en la toma de decisiones, como el otorgamiento de las becas. Además, debía cumplir con las instrucciones recibidas por Vasconcelos y, así, procuraba evitar que se cometieran errores, asimismo, se preocupó también por la buena distribución de las becas.

El mexicano realizaba giras por los países centroamericanos, por ejemplo, en 1923, viajó de Guatemala a Honduras, junto con Miguel Ángel Asturias, para visitar algunos diarios y dictar conferencias sobre la Universidad Popular. En una editorial del periódico hondureño Excelsior fue calificado como "protector del obrerismo hondureño" (Excelsior, 9 de mayo de 1923. Anexo, Bojórquezsu expediente, 1923-1924, citado por Díaz, 2008, pp. 2076-2077).

Las fuentes consultadas muestran que el trabajo político y cultural desempeñado por Bojórquez en Honduras propició el acercamiento con México. De hecho, años después, diría "en Honduras se quiere a México", cuando rememoró su paso por ese país:

De Centroamérica, Honduras es la nación en que más quieren a México. Los hondureños tienen muchos puntos de semejanza con los mexicanos. Díganlo sino algunos de los que pasaron por aquí: Matías Oviedo, Alfonso Guillén Zelaya, Rafael Heliodoro Valle y el tribuno revolucionario Ricardo D. Alduvín (Bojórquez, 1963, p. 192).

Afirmando así lo que sostenía en la correspondencia enviada desde Guatemala a la Secretaría de Relaciones Exteriores de México, el 23 de mayo de 1923, donde señalaba que Honduras era "la tierra que más se parece a nosotros y mejor nos comprende". Ante esa favorable situación recomendaba que el gobierno de México, "con toda la discreción del caso" para evitar que las gestiones se interpretaran como intromisión en los asuntos interiores de otro país, debería trabajar en la fusión del Partido Liberal, para evitar el triunfo de los conservadores (Bojórquez- su expediente, 8 de agosto de 1923). La Secretaría de Relaciones Exteriores de México envío un memorándum al ministro apoyando su moción.

En el ámbito periodístico e intelectual, la labor desempeñada por Bojórquez fue apreciada, por ejemplo, el periodista nicaragüense Hernán Robleto reconocía, en un artículo titulado "Crónicas de México. Los periodistas diplomáticos", que el ministro había hecho, en poco tiempo, más labor que todas las delegaciones que México ha mantenido en sus vecinos del Sur, fortaleciendo así, una política diferenciada con relación a Estados Unidos:

Ha encausado, sin mucho protocolo, sin mucho discurso de ocasión, una enorme corriente de simpatía hacia esta su tierra tan buscada y querida por los centroamericanos; ha hecho avanzar a México más allá del Suchiate, entrándosenos, no 
con tropas invasoras ni conquistadoras concesiones capitalistas, ni pactos internacionales, sino con la efectiva y duradera arma de los sentimientos francos, de su mano abnegada y fuerte que cruzan las venas de una sangre común (El imparcial, 18 de octubre, 1924, p. 5, citado por Díaz, 200b, p. 2078).

Para Robleto, Bojórquez, "el simpático muchacho socialista", tenía la ventaja de ser periodista. Esto le permitía sondear "las muchedumbres", indagar sobre las necesidades y aspiraciones colectivas, por eso podía desempeñar mejor los cargos diplomáticos.

El ministro fomentaba, además, las relaciones comerciales e intelectuales entre México y Guatemala. En 1923 organizó un viaje a su país acompañado del subsecretario guatemalteco de Fomento, Ricardo H. Peralta, y del redactor del periódico El Imparcial y miembro de la junta directiva de la Universidad Popular, David Vela. En el aspecto comercial pretendió realizar gestiones que favorecieran las exportaciones de ganado guatemalteco a México, para esto el subsecretario se entrevistó con el presidente Obregón. Las gestiones posiblemente fructificaron porque en esos años México, después de una década de revolución, necesitaba importar artículos de primera necesidad, como ganado vacuno y porcino, azúcar, maíz, arroz, trigo, manteca y otros artículos de primera necesidad (Zorrilla, 1984). Por su parte, David Vela llevaba la misión de saludar, a nombre de las Universidades Nacional y Popular de Guatemala, al presidente, a Vasconcelos, Secretario de Educación y a Antonio Caso, rector de la Universidad Nacional de México.

El amplio espectro de acción de Bojórquez, también gestionaba la disminución de horas de viaje México-Suchiate a partir del mejoramiento de las vías de comunicación, lo que favorecería el turismo y los negocios. Las actividades fomentadas por él eran consideradas como la "forma práctica en que se significan las relaciones de México con Guatemala". Días después del regreso de la delegación, se anunció la llegada del poeta Alfonso Cravioto (quien después sería nombrado embajador en Guatemala), como representante de la SEP, a iniciativa de la invitación que el colombiano Porfirio Barba Jacob, uno de los fundadores de la Universidad Popular, había hecho a Vasconcelos.

El arduo trabajo desarrollado por Bojórquez tuvo resultados positivos. Es claro que despertó en una parte del sector intelectual guatemalteco admiración por los cambios surgidos de la Revolución mexicana y por la política cultural difundida en la región a partir de diversos mecanismos que vincularon lo cultural, lo político y comercial. Baste decir que los redactores y colaboradores de El Imparcial, como mencionamos, eran conocidos como los "mexicanistas".

Aunque Bojórquez ocupó un lugar central en el diseño y aplicación de la estrategia mexicana hacia Centroamérica durante la década de 1920, hasta ahora ha sido poco estudiado. A partir de su trabajo es posible rastrear con mayor profundidad el impacto mexicano en la región durante el periodo de nuestro estudio. Vasconcelos, refrendando la importancia de las acciones que 
emprendió en la región, lo llamaba "Diputado por Centro América" (Bojórquezsu expediente, 1923-1924).

\section{Manuel Gamio}

Manuel Gamio (1883-1963), considerado el arqueólogo mexicano más importante de la década de 1920, alumno de Franz Boas en la Universidad de Columbia, fundó en 1917 la Dirección de Antropología y realizó diversos estudios arqueológicos y antropológicos. En 1920 publicó la revista Ethnos dedicada a la difusión de investigaciones arqueológicas. A finales de 1925, fue nombrado miembro de la American Archaeological Society de Washington para realizar investigaciones arqueológicas en Guatemala en Kaminaljuyú y en la finca "Miraflores", propiedad de Antonio Batres Jáuregui (destacado abogado y escritor, miembro fundador de la Sociedad de Geografía e Historia de Guatemala), como lo hiciera en Teotihuacan. Con este fin, Gamio eligió como colaborador al escultor guatemalteco Rafael Yela Günther, quien también había participado en los trabajos en esa zona arqueológica.

Su investigación, ligada a la escuela norteamericana, permitió ordenar las etapas culturales locales y acercarse a otras cuestiones del arte maya. Además, se comprobaron conexiones diversas con otras regiones y, en particular con Teotihuacan. En Guatemala, la Sociedad de Geografía e Historia publicó en sus Anales algunos de sus trabajos.

En junio de 1925, El Imparcial se refería a la presencia de Gamio como parte de la legación mexicana y como uno de los etnólogos de mayor preparación que poseía México y por serlo "cree con fe de sabio y fuerza de hombre en la redención del indio" (El Imparcial, 13 de junio de 1925, p. 6). Su idea de "hacer patria" era considerada como loable, sobre todo, por sus afanes de redimir al indio, creando, así, una patria que no estuviera al margen de la civilización.

El 20 de abril de 1926 se anunciaba el fin de la estancia de Gamio en Guatemala. Partía a los Estados Unidos para presentar el resumen de sus estudios y trabajos efectuados en ese país. Según un articulista las lecciones que el arqueólogo dejaba eran:

Una corriente de vida nueva, un deslumbramiento de cosas grandes y bellas, un inquebrantable apego de amor hacia la raza indígena, fe ardua en su porvenir y entusiasmo patriótico de labrar concienzudamente su destino, es lo primero que se hereda de una plática con este hijo preclaro de la nación azteca (Arqueólogo azteca nos abandona. Va a Washington el doctor Gamio, En las simas del pasado, 20 de abril de 1926, p. 1).

Por su parte, Gamio consideraba que México había señalado los derroteros para la aplicación de la arqueología en el conocimiento de las raíces de la historia de los pueblos indohispánicos. Reconocía que países como México y Guatemala eran herederos de una civilización asombrosa, pero que era necesario 
estudiarla científicamente, de lo contrario sus enseñanzas quedarían perdidas. Además, establecía el nexo entre el pasado y el presente indígena, la no existencia de razas superiores y la necesidad de la incorporación de los indígenas para cambiar la situación de los países. Convertirlos así "en un actor de avance y no en un lastre" (El Imparcial, 20 de abril, 1926, p. 1).

La presencia de Gamio en Guatemala propició una mayor difusión de su trabajo arqueológico y antropológico, el cual era conocido desde años antes. Además, fomentó la discusión en torno a la necesidad de crear una dirección encargada de los estudios en esas áreas. Para M. Castro y Morales, el mejor esfuerzo que se había hecho en relación con la difusión de los estudios arqueológicos era la creación de la Dirección General de Antropología en México (1917), dirigida por Gamio (Castro y Morales, 1923).

Además, se mencionaba la urgencia de fundar en Guatemala la Escuela de Antropología y relacionarla con las de México y Perú. Un decreto presidencial, dictado en 1922, disponía la creación de la Dirección General de Arqueología, Etnología e Historia. Tendría como anexo un Museo Nacional (El Imparcial, 24 de julio de 1922, p. 3).

El reconocimiento de la importancia de los estudios antropológicos en Guatemala no solo llegó de México, también de Perú. En 1924, José Antonio Encinas (quien en ese entonces se encontraba en Guatemala porque había sido deportado por el gobierno de Augusto B. Leguía) dio una conferencia sobre la importancia, finalidad, carácter científico y organización de ese tipo de estudios en el mundo, especialmente para los países hispanoamericanos. Para el peruano la necesidad de aplicar el estudio científico de la población indígena, dejando el afán empírico que había caracterizado a los gobiernos, era urgente en su país, debido al carácter "levantisco y rebelde del trabajador indio; unida a su ineducación y, por así decirlo, a su impermeabilidad mental para asimilarse a nuestra civilización". Habría que poner un alto a tal situación, de lo contrario se presagiaban terribles conmociones sociales (El Imparcial, 5 de febrero de 1924, p. 5). Estas ideas coincidían con el pensamiento guatemalteco de esos años.

Encinas consideraba que la antropología (que incluía la filología, la etnografía, la geografía física) estaba relacionada con el movimiento nacionalista de México. Para que ese movimiento fructificara en otros países era necesario "exhumar el alma de nuestros antepasados y derivar de ella el sentido vivo y espiritual de nuestra nacionalidad: he aquí la idea" (El Imparcial, 5 de febrero de 1924, p. 5).

El trabajo de Gamio sobre el Valle de Teotihuacan también era reconocido como una muestra del tipo de investigaciones que se deberían realizar en Guatemala "con la verdadera historia de los aborígenes americanos". Además, se tenían noticias del teatro, único en su clase, construido para los indígenas de ese poblado para que realizaran representaciones. Estas eran calificadas por 
El Imparcial como "llenas de instintivo buen gusto y con el hondo sentimiento de su raza" (El Imparcial, 12 de noviembre de 1924, p.1).

En los Anales de Sociedad de Geografía e Historia, de la cual Gamio era socio honorario, se publicó su trabajo "El mestizaje eugenésico en la población de la América indo-ibérica" (Anales de la Sociedad de Geografía e Historia, 1930). En este sintetizaba su idea del mestizaje. Gamio consideraba que la región que iba desde el Río Bravo hasta el Estrecho de Magallanes era de las más ricas en el mundo por su diversidad de materias primas y su potencialidad agrícola. Sin embargo, su problema mayor radicaba en el aspecto racial, debido a que la mayoría de la población era aborigen y la población blanca, una minoría. Esta situación, según Gamio, no resultaba favorable para los países de esa región, sobre todo, si le comparaba con Estados Unidos, mayoritariamente blanco y con una producción agrícola mayor.

El arqueólogo-antropólogo sugería que para terminar con "tal anomalía" era necesario "procurar el rápido y total mestizaje de la población, o sea la fusión racial de los elementos indígenas y blancos, lo que indudablemente se lograría se consideraba el problema desde los puntos de vista económico y eugenésico (Anales de la Sociedad de Geografía e Historia, 1930, p. 334).

Manifestaba, también, que el problema económico se resolvería mejorando la situación económica del indio a través de dos mecanismos, el reparto de tierras y la educación industrial, a fin de que pudiera hacer uso de los recursos naturales que le brindaba su país. Por lo tanto, no era necesaria la extinción de los indígenas, como consideraban algunos. Ponía énfasis en que la separación de blancos e indios no se daba en el ámbito racial, sino, en los aspectos económico y cultural. El indio era rechazado por su miseria e ignorancia, no por su sangre.

El problema racial se resolvería a partir del mestizaje, puesto que de esa manera la población de América Latina "aumentará numéricamente y mejorará su desarrollo cultural, cuando dicha población sea racialmente homogénea" (Anales de la Sociedad de Geografía e Historia, 1930, p. 335). Sin embargo, la fusión de razas no implicaba que se hiciera solo con los habitantes de dichos países, de ser así, dada la mayoría indígena, los blancos serían absorbidos por esta. Por lo tanto, consideraba necesaria una profusa inmigración blanca europea, seleccionada: "en otras palabras, la civilización moderna de las minorías blancas retrogradaría en su evolución al fundirse con la indígena de las mayorías que presenta varios siglos de retraso, lo que naturalmente sería perjudicial en alto grado y por tanto inaceptable" (Anales de la Sociedad de Geografía e Historia, 1930, p. 335). Para el logro del proyecto de mestizaje recomendaba la investigación antropológica de la población indígena (prioritariamente) y blanca. Con este fin, el Estado debería facilitar los medios necesarios.

Las ideas de Gamio, polémicas y contradictorias, influyeron en las interpretaciones de algunos intelectuales guatemaltecos, como Villacorta, Asturias 
y Juárez Muñoz. Aunque ellos no lo reconocieran abiertamente, los planteamientos de sus trabajos en la década de 1920 y posteriores, así lo muestran. Es necesario puntualizar que, para entonces, las ideas iban y venían por todo el continente, se mezclaban con el pensamiento europeo o norteamericano. Por esto, es difícil determinar la originalidad de los planteamientos. No obstante, la ideología de los mexicanos de dicha época puede considerarse como la vanguardia en los estudios arqueológicos y antropológicos. En Guatemala, las investigaciones de ese tipo estuvieron bajo el control norteamericano, lo que dificultó el desarrollo de una arqueología y antropología guatemalteca.

\section{Daniel Cosío Villegas}

Como mencionamos, Daniel Cosío Villegas (1898-1976) viajó a Guatemala en 1924, para entonces ya era conocido por los estudiantes de ese país por haber sido presidente del Congreso Internacional de Estudiantes, realizado en México en 1921. Proveniente de un viaje por El Salvador, la Universidad Popular lo invitó a dar una conferencia. Su labor fue considerada de "gran provecho para la renovación ideológica" de los estudiantes.

Cosío Villegas en sus Memorias menciona que, en 1924, viajó por primera vez a Guatemala como delegado estudiantil, cuando Bojórquez se desempeñaba como ministro. Estando en Centroamérica, llamó su atención el destacado trabajo que el diplomático desempeñaba como parte de la política mexicana de acercamiento por iniciativa propia. Según Cosío Villegas, Bojórquez hacía dos viajes anuales a México y volvía a Guatemala llevando algún espectáculo: una exposición de pintura, un equipo de fútbol, algún pequeño grupo teatral, recitadores, cantantes y bailarines. Cuando los gastos no eran costeados por Relaciones Exteriores, el ministro acudía al general Francisco Serrano y al coronel Celis. Este último agregado militar de la Legación de México en Guatemala (Cosío Villegas, 1986, p. 105). Con la presencia de Cosío Villegas en el istmo nos acercarnos a las redes que se establecieron entre los experimentados diplomáticos con los jóvenes intelectuales, entre los cuales destaca Miguel Ángel Asturias.

\section{Antonio Caso}

Si bien el intelectual más destacado en el ambiente intelectual latinoamericano fue Vasconcelos, Antonio Caso (1883-1946) también fue considerado como un ejemplo para la juventud centroamericana. No hay referencias que indiquen su paso por algún país centroamericano, sí las hay de países sudamericanos. En 1921, el gobierno mexicano, le encomendó viajar a los actos conmemorativos de la independencia peruana, luego su viaje se amplió de Lima, a Santiago, Buenos Aires, Montevideo y Río de Janerio. En estas ciudades dictó conferencias y se relacionó con intelectuales y estudiantes (Yankelevich, junio de 1999). 
En los países centroamericanos, su figura y algunos puntos de su pensamiento fueron ensalzados en diarios y revistas. Se destacó su labor como educador, de transmisor de ideas a los jóvenes centroamericanos que se encontraban en México. Se esperaba que ellos aportaran sus conocimientos al engrandecimiento del pensamiento y de la educación en Guatemala. En ese contexto se preguntaba un periodista: ¿sería necesario esperar hasta entonces para lograr mayor disciplina del estudio en la educación universitaria? (Avilés, 2 de junio de 1923, p. 13). Refiriéndose a Centroamérica, el pensador mexicano señalaba:

Me imagino muy claramente el esfuerzo combinado de las Universidades latinoamericanas, precursor de la Asociación Internacional de nuestros pueblos. Creo que con especialidad que la Universidad de México podría convertirse en un centro de acción intelectual con las Repúblicas Centroamericanas, núcleo que al vigorizarse y difundir sus elementos de cultura por los países más íntimamente relacionados con el nuestro en el continente, alcanzaría su máximo de esplendor y su más noble y profunda acción humana. Los intereses políticos, económicos y sociales de México y Centro América, son idénticos (Caso citado por Avilés, 2 de junio de 1923, p. 13).

Así, Caso coincidía con Vasconcelos en la idea de convertir a México en centro intelectual de América Latina, específicamente de Centroamérica. La unidad latinoamericana se conseguiría a partir del pensamiento y la educación.

\section{Moisés Sáenz}

Moisés Sáenz (1888-1941), subsecretario de educación pública de 1924 a 1928 y promotor del Instituto Nacional de Misiones Culturales y de la Casa del Estudiante Indígena, viajó en 1931 a Guatemala como vocal de la Comisión Técnica Consultiva de Educación Pública de México y Delegado de la Comisión de Investigaciones Indias del gobierno de su país. Su misión consistía en estudiar las instituciones docentes de Centro y Sur América y, especialmente, hacer observaciones de la incorporación cultural del indio (Carta de Eduardo Hay dirigida al Ministro de Relaciones Exteriores de Guatemala, Alfredo Skinner Klee, 2 de septiembre de 1931). Por este encargo oficial permaneció varias semanas recorriendo varios puntos de Guatemala. Según Eduardo Hay, Secretario de Relaciones Exteriores de México, en una carta dirigida al Ministro guatemalteco, los estudios de Saénz redundarían en el mejor conocimiento de sus países, lo que era tan conveniente fomentar.

En el expediente personal de Sáenz que se encuentra en el Archivo Histórico de la Secretaría de Relaciones Exteriores de México, se cruza información no solo proveniente de Guatemala, sino también de Perú, debido a que realizó investigaciones en ese país, como parte del mismo programa que lo llevó a Guatemala y a Ecuador. El viaje de Sáenz expresaba el interés del gobierno mexicano en la difusión de su política indigenista en países con alto número de indígenas. 
La legación de México en Lima señalaba que los diarios conservadores no habían dado importancia a la visita de Sáenz porque su respeto por México "llegaba al miedo". Por su parte, La Tribuna (órgano aprista) y algún otro diario independiente le dieron la bienvenida, al igual que los intelectuales que le brindaron atenciones especiales. Las autoridades del Ministerio de Instrucción, según el diario, gente en su mayoría de tendencias más modernas que las otras dependencias, "comprendió bien la importancia que podía tener para el Perú la visita de Profesor Sáenz" (Carta de Juan G. Cabral, Ministro de México en Perú, al Secretario de Relaciones Exteriores de ese país, 30 de enero de 1932).

Por su parte, el rector de la Universidad de San Marcos, José Antonio Encinas, reconocido educador peruano, cuyo mexicanismo era apreciado, lo invitó a dar dos conferencias, la primera referida al espíritu y métodos de la nueva escuela rural mexicana y de la amplia labor que por ese medio desarrolla la SEP. También ofreció otras conferencias dirigidas a la intelectualidad peruana referidas al problema agrario en México.

Después de su estancia en Lima se dirigió a diversas poblaciones de la sierra, visitando los centros escolares que allí existían. También estuvo en Arequipa y en Cuzco, donde dictó conferencias. Sáenz se mostró satisfecho de sus estudios y observaciones en esa región del Perú, donde los indígenas tenían una fuerte presencia.

El representante mexicano en el país andino en su informe al Secretario de Educación Pública, Narciso Bassols, señalaba: "es interesante notar que, coincidiendo con la vista el Prof. Sáenz, el Gobierno de este país acaba de expedir tres decretos relativos a cuestiones indígenas: la fundación de la Escuela Normal Rural del Cuzco, anexo a la Granja Escuela de Kaira; la exposición permanente de arte indigenista escolar y popular y el Congreso Indigenista que, posteriormente, ha sido postergado (Carta de Juan G. Cabral, Ministro de México en Perú, al Secretario de Relaciones Exteriores de ese país, 30 de enero, 1932).

El balance de la visita de Sáenz al Perú, hecho por esa secretaría, era positivo porque, además de sus estudios, le había permitido vincularse cercanamente con los mejores elementos de ese país y avivar en ellos el interés por las cosas de México. En 1935, Sáenz fue designado embajador de México en Perú. Entonces el diario peruano La Crónica se refería a Sáenz de esta forma: "es posiblemente, la autoridad americana en todo cuanto concierne, al problema de incorporar 30 millones de andinos al nivel de vida y de cultura de los mestizos y blancos del Nuevo Mundo" ("Sáenz, el investigador indigenista, nuevo ministro de México en el Perú", 14 de diciembre de 1935). El diario peruano citaba lo dicho por Saénz en su trabajo Sobre el indio peruano y su incorporación al medio nacional:

Creo que el indio, pese a su mutismo y pasividad tendrá que forzar la puerta de salida; tendrá que hablar por su propia voz y clamar por sus derechos humanos 
para asegurar después, por sí mismo, sus derechos políticos. Pero cuando esto suceda el indio ya no será indio, se habrá amestizado; si lo queremos será uno de nosotros. SERA NOSOTROS MISMOS. Esto es lo que quiere decir "la incorporación del indio" (Sáenz, el investigador indigenista, nuevo ministro de México en el Perú, 14 de diciembre de 1935).

Las referencias a Sáenz en Perú coinciden con las que se hicieron en Guatemala en relación con los proyectos encaminados a la "incorporación" del indio. Por ejemplo, se decía que a él se debía en mucho "la reforma educacional mexicana creando escuelas rurales, internados indígenas, escuelas ambulantes, talleres escolares, etc. que favorecen directamente al niño indígena" (“Sáenz, el investigador indigenista, nuevo ministro de México en el Perú”, 14 de diciembre de 1935).

Según la revisión realizada hasta el momento, la estancia de Sáenz por Guatemala tuvo menor resonancia que la de Gamio, sin embargo, algunas de sus propuestas, como la creación de la Casa del Estudiante Indígena, fueron bien recibidas. Este proyecto estaba relacionado con su concepción de una educación diferenciada, es decir, la educación indígena debería contar con sus propias formas de desarrollo. Su concepción se oponía a la difundida por Vasconcelos: "no apoyamos, entonces al sistema yanqui de escuelas especiales para indios, sino al sistema criollo de llevar al indio a la misma escuela nacional que lo asocia al blanco" (Vasconcelos, 1968, pp. 1604-1605).

Tal visión fue la dominante durante los primeros años de la década de 1920, sin embargo, ante las dificultades que se presentaron, debido a la diversidad lingüística, y a la existencia de comunidades monolingües, se creó en 1926, la Casa del Estudiante Indígena, con la finalidad de incorporarlo, "con medios más eficaces", a la civilización mestiza y occidental. Esto en el gobierno de Calles, entonces José Manuel Puig Casauranc era el Secretario de Educación y Moisés Sáenz, el subsecretario.

La creación de esta institución pretendía eliminar la distancia que separaba a los indígenas de la sociedad nacional y de esa manera poder incorporarlos a la "gran familia mexicana" (Dawson, 2001, pp. 329-361). En 1932, la Casa del Estudiante Indígena fue cerrada, la mayoría de los indígenas que habían participado en dicho proyecto no regresaron a sus comunidades para que funcionaran como "agentes aculturadores".

El proyecto de la Casa del Estudiante Indígena fue ampliamente difundido y discutido en los periódicos guatemaltecos, sin considerar sus contradicciones, por eso, se pensó que era un buen modelo que se podía seguir en Guatemala. En 1928, el diario guatemalteco Excelsior, designó páginas completas al tema de la educación del indio en México. Esto coincidió con la presencia de su propietario, Eduardo Aguirre Velásquez y Juan José Arévalo, uno de sus editorialistas, en México. En agosto de ese año apareció un editorial de página completa, donde se señalaban a detalle los rasgos de "La Escuela del Indio" (conocida 
en México como la Casa del Indio). Una de las virtudes de esta era que daba respuesta a cómo instruir de la mejor manera a la población aborigen, lo cual era posible formando maestros indígenas. Estos tenían la ventaja de poseer el idioma de quienes iban a instruir. Esta medida, apoyada por Calles, fue calificada como patriótica (“La educación del indio", 25 de agosto de 1928, p. 3).

El artículo de Juan José Arévalo, dedicado a la Casa del Estudiante Indígena, ocupó un espacio considerable en Nuestro Diario y fue dedicado al Consejo Nacional de Educación para que pusiera atención en el asunto. El normalista reseñó su visita a la Casa y puso énfasis en los beneficios que traería para los indígenas y para Guatemala si se aplicara ese modelo educativo. Aunque el proyecto de la Casa no fue precisamente de Vasconcelos, Arévalo lo consideraba su fundador. Nuevamente se reafirmaba que la finalidad de la institución era la "asimilación de las razas aborígenes a la civilización" (Arévalo, 18 de agosto de 1927, p. 5.)

Las observaciones realizadas por Moisés Sáenz en Guatemala no fueron publicadas, contrariamente a lo que sucedió con sus estudios referidos a Perú y a Ecuador. Esto dificultó la reconstrucción del significado de esas investigaciones, sin embargo, los datos existentes ponen en evidencia que los temas que le preocupaban se discutían en la región, especialmente, en Guatemala, sin embargo, en la década de 1920, no había viajado a este país y probablemente sus ideas se confundían con las de Vasconcelos, como se señala en líneas anteriores.

Los viajes emprendidos por Sáenz a Guatemala, Perú y Ecuador, a principios de la década de 1930, contribuyeron a enriquecer su visión y concepción de la educación indígena y rural. Esto lo llevó a plantear nuevos proyectos relacionados con la población indígena. Los viajes de estudio de Sáenz, dejan abiertas múltiples vetas para acercarnos a la discusión en torno al "problema indígena" en los años de estudio y posteriores.

\section{Conclusiones}

La revisión que hemos realizado en este trabajo nos permite establecer que, en las dos primeras décadas del siglo XX, las relaciones culturales y políticas de México y Centroamérica se intensificaron. El primero impulsó una política que fomentó el acercamiento con la región, cuya recepción y significación no fue homogénea, si embargo, en el sector intelectual fueron positivas porque los ideales de una generación coincidieron con los planteamientos de la Revolución mexicana de 1910 y con el diseño de políticas encaminadas a la transformación de la sociedad. En este sentido, las ideas iban y venían entre México, Centroamérica y el resto del subcontinente latinoamericano, propiciando la discusión y el conocimiento mutuo. Así, nos acercamos a las distintas propuestas de nación y a los proyectos que se debatían. 
Los intelectuales mexicanos, algunos, como Vasconcelos y Bojórquez con una intensa actividad de difusión de la cultura y de la política, otros en la realización de investigaciones que pretendían explicar el pasado y el presente de sus países, contribuyeron a la difusión de una lectura de la realidad latinoamericana que atravesaba las fronteras.

Además, es importante señalar que los intelectuales mexicanos, que diseñaron y promovieron la estrategia de difusión de la imagen de México en el exterior, no era un grupo homogéneo, transitaban entre el pensamiento liberal, el antiimperialismo, el comunismo, corrientes espiritistas y otras. Sin embargo, los que se vincularon al Estado fueron quienes compartían el afán por la reconstrucción de la identidad nacional a partir del mestizaje, al cual se subordinó, en algunos casos, la presencia indígena.

También mencionemos que, en la década de 1920, la política, la diplomacia y la cultura estaban estrechamente vinculadas por constituir los pilares del proyecto del Estado mexicano. Así, las relaciones de este México con los países centroamericanos se pueden entender considerando las siguientes premisas:

-Se trata de relaciones entre Estados diferentes, el primero considerado como potencia media, y los segundos como Estados con menor influencia y poder de decisión en el ámbito internacional.

-En la relación bilateral, México intenta ser modelo de nación aplicando la pedagogía "del hermano mayor" de Centroamérica que confronta a los Estados Unidos.

-Se trata de países diferenciados en su proceso de desarrollo. México salía de una conmoción revolucionaria, mientras Guatemala, por ejemplo, de una larga dictadura que, no obstante la movilización para derrocar a Estrada Cabrera, su estructura político-social no sufrió cambios radicales.

Finalmente, como se evidencia, la política mexicana se centró en la difusión de ideas (en la cual contó con un importante apoyo de los intelectuales centroamericanos), en el control del transporte comercial, de las comunicaciones y la formación de cuadros destinados a propagar su imagen. Abarcando así, todos los ámbitos posibles para obtener resultados eficaces.

\section{Fuentes primarias}

Aguirre Velásquez, su expediente. (1922). Archivo Histórico de la Secretaría Relaciones Exteriores de México. Clasificación topográfica: 3-17-7. México.

Bojórquez, Juan de Dios, su expediente. (1923-1924). Archivo Histórico de la Secretaría de Relaciones Exteriores de México. Clasificación Topográfica 
Bojórquez, Juan de Dios, su expediente. (8 de agosto de 1923). Archivo Histórico de la Secretaría de Relaciones Exteriores de México. Clasificación Topográfica 1-17-24, Legajo II. México.

Boulletin periodique de la presse Sud-americaine. (20 de mayo de 1921). Archivo Histórico del Ministerio de Relaciones Exteriores de Francia. Sous série Centre-Amérique, carton 5, Union Centro-americaine. Francia.

Carta de Eduardo Hay dirigida al Ministro de Relaciones Exteriores de Guatemala, Alfredo Skinner Klee. (2 de septiembre de 1931). Sáenz, su expediente, Archivo Histórico de la Secretaría de Relaciones Exteriores de México. Clasificación Topográfica 35-13-13, Legajo I. México.

Carta de Juan G. Cabral, Ministro de México en Perú, al Secretario de Relaciones Exteriores de ese país. (30 de enero, 1932). Sáenz, su expediente, Archivo Histórico de la Secretaría de Relaciones Exteriores de México. Clasificación Topográfica 35-13-13, Legajo I. México.

El Comercio. (27 de enero de 1926). Archivo Histórico del Ministerio de Relaciones Exteriores de Francia. Sous série Centre-Amérique. Carton 2, 19241927. Francia.

Excelsior. (9 de mayo, 1923). Anexo, Bojórquez, su expediente, Archivo Histórico de la Secretaría de Relaciones Exteriores de México. Clasificación Topográfica 1-17-24, Legajo II. México.

Informe de la Legación de Guatemala en México. (1925). Memoria del Ministerio de Relaciones Exteriores. Guatemala: Tipografía Nacional.

Informe político No. 3. (6 de octubre de 1922). De Rodríguez al Ministro de Relaciones Exteriores de Guatemala, Adrián Recinos. Archivo General de Centroamérica. Signatura: B99-23-1, Legajo: 6236. Guatemala.

Informe político No. 13. (México 21 de marzo de 1923). De Rodíguez a Adrián Recinos, Ministro de Relaciones Exteriores. Archivo General de Centroamérica. Signatura: B99-23-1, Legajo: 6236. Guatemala.

Sáenz, el investigador indigenista, nuevo ministro de México en el Perú. (14 de diciembre de 1935). La crónica, Lima. Anexo. Sáenz, su expediente, Archivo Histórico de la Secretaría de Relaciones Exteriores de México. Clasificación Topográfica: 35-13-13, Legajo I. México.

\section{Referencias}

Aguilar de León, Juan de Dios. (1986). José María Orellana. Presidente de Guatemala, 1922-1926. Compilación documentada de la vida y obra del fundador de la moneda guatemalteca. Guatemala: Editor no identificado. 
Anales de la Sociedad de Geografía e Historia. (marzo de 1930). Año V, tomo VI, (3), Guatemala.

Arévalo, Juan José. (18 de agosto de 1927). La casa del estudiante indígena. Nuestro Diario, p. 5.

Arévalo Martínez, Rafael. (1925). La oficina de paz Orolandia. Guatemala: Tipografía Sánchez \& De Guise.

Arqueólogo azteca nos abandona. Va a Washington el doctor Gamio. En las simas del pasado. (20 de abril de 1926). El Imparcial, p 1.

Avilés, Juan Ramón. (2 de junio de 1923). Los nuevos hombres de México. El maestro Antonio Caso. El imparcial, p. 13.

Bibliotecas de la Casa del Niño. Valioso donativo de la Secretaría de Educación Pública de México. (3 de junio de 1925). El Imparcial, Guatemala.

Bodo Randrianarijaona, Pilar. (2004). Revista y Cultura: El libro y el pueblo. Centros y periferias, 45-58. Recuperado de http://dialnet.unirioja.es/descarga/articulo/1069902.pdf

Bojórquez, Juan de Dios. (1963). Hombres y aspectos de México. En la tercera etapa de la revolución. México: Instituto Nacional de Estudios Históricos de la Revolución Mexicana. Recuperado de http://biblio.juridicas.unam.mx/libros/libro.htm?l=3450

Castro y Morales. (diciembre de 1923). La Escuela de Antropología en la Universidad de Guatemala. Studium, (12), Guatemala.

Crespo, Regina. (2005). Itinerarios intelectuales: Vasconcelos, Lobato y sus proyectos para la nación. México: Centro Coordinador y Difusor de Estudios Latinoamericanos / Universidad Naciona Autónoma de México.

Cosío Villegas, Daniel. (1986). Memorias. México: Joaquín Mortiz / SEP.

Dawson, Alexander S. (enero, 2001). "Wild Indians", "Mexican gentlemen”, and the lessons learned in the Casa del Estudiante Indígena, 1926-1932. The Americas, 57(3), 329-361.

Díaz Vázquez, María del Carmen. (2008). Centroamérica en la estrategia diplomática mexicana: entre la política y la difusión cultural (1920-1932). Diálogos Revista Electrónica de Historia, número especial, 2060-2080.

El Imparcial. (24 de julio de 1922). Guatemala, p. 3.

El Imparcial. (5 de mayo de 1923). Guatemala, p. 3.

El Imparcial. (12 de noviembre de 1924). Guatemala, p. 1.

228 El imparcial. (13 de junio de 1925). Guatemala, p. 6. 
Fell, Claude. (1989). José Vasconcelos, Los años del águila. México: Universidad Nacional Autónoma de México.

Galeana, Patricia. (2014). Introducción. En Djed Bojórquez (ed.), Crónica del constituyente. México: Instituto de Investigaciones Jurídicas-Uiversidad Nacional Autónoma de México / Instituto Nacional de Estudios Históricos de las Revoluciones de México.

Galindo, Hermila. (1919). La doctrina Carranza y el acercamiento indolatino. México: Editor no identificado.

García Rey, María del Rocío. (2010). Centroamérica en El maestro. Revista de Cultura Nacional. X Congreso Centroamericano de Historia, llevado a cabo en la Universidad Nacional Autónoma de Nicaragua, Managua, Nicaragua. Recuperado de http://www.hcentroamerica.fcs.ucr.ac.cr/index. php?option=com_content\&view=article\&id=416\&ltemid=20

González y González, Luis; Mora Plancarte, Norberto \& Cámara de Diputados del Congreso de México. (1966). Los presidentes de México ante la nación. Informes, manifiestos y documentos de 1821 a 1966. México: Imp. de la Cámara de Diputados.

Hemiplejia de la educación. El libro caro. (24 de mayo, 1923). El Imparcial, p. 3. Homenaje del Liceo de Costa Rica al Licenciado Vasconcelos y a "Miss Costa Rica". (6 de abril, 1930). La Tribuna, p. 1.

Laudable labor de la Secretaría de Educación Pública de México. (13 de noviembre de 1922). El Imparcial. p. 1.

Lempérière, Annick. (1988). Mexico "fin de siecle" et le "modele français", en L’Amérique Latine et les modèles européens. Paris: L'Harmattan.

Robleto, Hernán. (18 de octubre de 1924). Crónicas de México. Los periodistas diplomáticos. El imparcial, p. 5.

Rodríguez Beteta, Virgilio. (1980). No es guerra de hermanos sino de bananos. Como evite la guerra en Centroamérica en 1928. Guatemala: Editorial José de Pineda lbarra.

Rosales, Salatiel. (1 de marzo de 1924). La diplomacia de México. El imparcial, p. 3.

Skirus, John. (1978). José Vasconcelos y la cruzada de 1929. México: Siglo XXI.

Taracena Arriola, Arturo (octubre-diciembre, de 2010). Vasconcelos y sus agentes en la recepción guatemalteca de la Revolución mexicana. Regiones, suplemento de antropología, (43), 25-31. Recuperado de http://www.suplementoregiones.com/suplementos/043/a04.html 
Vázquez de Knauth, Josefina. (1979). Nacionalismo y educación en México. México: El Colegio de México.

Wilkie, James W. \& Monzón Wilkie, Edna. (2001). Frente a la Revolución Mexicana (17 protagonistas de la etapa constructiva) (vol. II). México: Universidad Autónoma Metropolitana.

Yankelevich, Pablo. (1997). Miradas australes. Propaganda, cabildeo y proyección de la Revolución Mexicana en el Río de la Plata, 1920-1930. México: Instituto Nacional de Estudios Históricos de las Revoluciones de México / Secretaría de Educación Pública.

Yankelevich, Pablo. (Junio de 1999). Cuando Antonio Caso conoció Sudamérica. Revista de la Universidad Nacional. Recuperado de http://www. revistadelauniversidad.unam.mx/ojs_rum/files/journals/1/articles/14916/ public/14916-20314-1-PB.pdf

Zorrilla, Luis G. (1984). Relaciones de México con la República de Centroamérica y con Guatemala. México: Porrúa. 